\title{
Padre Vaz no meu caminho filosófico
}

\author{
Father Vaz on my philosophical path
}

Marcelo Perine

https://orcid.org/0000-0003-2264-6737 - E-mail: mperine@gmail.com

\begin{abstract}
RESUMO
O texto é um depoimento sobre o papel desempenhado pelo Padre Vaz na minha formação filosófica e em parte expressiva da minha produção intelectual, tanto pela relação de amizade estabelecida nos anos de companheirismo como jesuítas, como pela assídua frequentação de seus textos até hoje. A rememoração é também um gesto de agradecimento ao filósofo, mestre e amigo incomparável.
\end{abstract}

Palavras-chave: Padre Vaz. Filosofia. Formação. Amizade.

\begin{abstract}
The text is a testimony about the role played by Father Vaz in my philosophical formation and in a large part of my intellectual production, both because of the friendship established in the years of companionship as Jesuits, and due to the frequent attendance of his texts until today. Remembrance is also a gesture of gratitude to the incomparable philosopher, teacher and friend.
\end{abstract}

Keywords: Father Vaz. Philosophy. Formation. Friendship. 
E não dizemos que a reminiscência difere da memória? Platão, Filebo 34b

O título deste depoimento é um decalque do título de uma conferência proferida no IV Colóquio Vaziano de Belo Horizonte em 2011, posteriormente publicada na Revista Síntese como Platão no caminho filosófico de Lima Vaz (PERINE, 2012). Inspirando-me em Platão, que entrou no caminho filosófico de Lima Vaz desde o início ${ }^{1}$, minha contribuição ao dossiê em homenagem ao Padre Vaz não pretende ser um simples exercício de memória (mnéme), mas de reminiscência (anámnesis). Com efeito, na sequência do diálogo de onde a epígrafe acima foi extraída, Sócrates explica a Protarco em que consiste a diferença. Reminiscência ocorre quando "a alma sozinha e em si mesma, sem o corpo, recupera, o quanto possível, as afecções que uma vez experimentou com ele", e "também, quando, depois de perder a memória de uma sensação, ou de um aprendizado, ela os recobra novamente, sozinha em si mesma" (Filebo 34bc). A diferença está entre a simples conservação passiva de sensações e a reprodução ou recuperação de sensações e de conhecimentos pela atividade da alma².

Fazer a anamnese da presença do Padre Vaz em meu caminho filosófico me remete também ao início do caminho. No final de 1980, quando estava para concluir os estudos de teologia na PUC-Rio, fui "destinado" (este é o jargão jesuíta para o caso) a fazer o doutorado em filosofia na Universidade Gregoriana de Roma. Consultei o Padre Vaz, que era meu superior religioso, sobre eventuais autores sobre os quais fazer o doutorado. A conversa resultou decisiva para a minha escolha. O conselho determinante foi o de fazer a tese sobre um filósofo que me proporcionasse o contato com a grande tradição de pensamento filosófico do Ocidente e, segundo o Padre Vaz, um desses filósofos era Éric Weil, naquele momento um ilustre desconhecido para mim. Passados quase quarenta anos daquela conversa, estou absolutamente convencido de que o Padre Vaz tinha razão. A propósito, dar razão e ter razão é tudo a que um verdadeiro filósofo pode aspirar.

Não tive a oportunidade e a fortuna de ser aluno do Padre Vaz. Em compensação, ao regressar ao Brasil após a conclusão do doutorado sobre Eric Weil ${ }^{3}$, no início de 1986, tive o privilégio de conviver com Padre Vaz na comunidade dos professores e trabalhar com ele na Faculdade de Filosofia dos Jesuítas em Belo Horizonte. Herdei a sua disciplina de História da Filosofia Antiga, recebi dele a direção da Coleção Filosofia de Edições Loyola, recém fundada por ele e, posteriormente, a editoria da Revista Síntese.

Foram anos de intensa atividade acadêmica e editorial. Como Diretor da Coleção Filosofia, preparei a publicação do segundo volume de seus Escritos de Filosofia (LIMA VAZ, 1988) e os dois volumes da sua Antropologia Filosófica (LIMA VAZ, 1991; 1992). Estimulado por ele, empreendi a tradução da História da Filosofia Antiga, em cinco volumes, de Giovanni Reale. Nesse projeto o Padre Vaz empenhou-se diretamente, tendo traduzido a parte referente a Platão do segundo volume e a parte dedicada a Plotino do quarto volume, além de alguns ver-

\footnotetext{
1 A tese de doutoramento do Pe. Vaz, apresentada à Faculdade de Filosofia da Pontifícia Universidade Gregoriana de Roma, orientada pelo Pe. René Arnou, SJ, foi depositada no dia 6 de dezembro de 1952 e defendida no dia 29 de janeiro de 1953. Em preciosa tradução do latim feita por Juvenal Savian Filho, a tese inaugurou a coleção "Obra filosófica inédita de Henrique Cláudio de Lima Vaz". (Cf. LIMA VAZ, 2012).

${ }^{2}$ A reminiscência, portanto, é uma espécie de meta-memória que age num nível superior ao da memória: enquanto a memória é um receptáculo passivo, na maioria das vezes ligada à sensação e ao corpo, a reminiscência é ativa e refere-se unicamente à alma. (Cf. MIGLIORI, 1993, p. 200 s).

${ }^{3}$ Minha tese sobre Éric Weil (PERINE, 1987, 2. edição 2013) inaugurou em nossa academia um campo de estudos povoado hoje por excelentes professores e pesquisadores como Marly Carvalho Soares, Evanildo Costesky, Sergio de Siqueira Camargo, Daniel Fonseca Lins Junior, Daniel Benevides Soares, Aparecido de Assis, Francisco Valdério e Judikael Castelo Branco, entre outros.
} 
betes do Léxico (volume V). O primeiro volume foi apresentado ao público no encerramento da Primeira Semana Filosófica, que organizei em agosto de 1991, para comemorar os cinquenta anos da Faculdade de Filosofia da Companhia de Jesus e os setenta anos do Padre Vaz, seu mais ilustre aluno e mais célebre professor. As Atas desta semana foram publicadas em volume especial da Revista Síntese ${ }^{4}$. Remeto o leitor benévolo à memorável Lectio magistralis pronunciada pelo Padre Vaz no encerramento da Semana Filosófica, com o emblemático título de "Morte e vida da filosofia", que, a meu ver, pode ser lida como uma espécie de testamento filosófico do Padre Vaz (LIMA VAZ, 1991a).

Como Editor da Revista Síntese, trabalhei em grande sintonia com o Padre Vaz no planejamento dos números, na análise e seleção dos textos a serem publicados. Nesse período o Padre Vaz publicou um texto que teve grande impacto na minha reflexão e produção acadêmica posterior. Em 1988, ano de grande efervescência política nacional, o Padre Vaz publicou uma penetrante reflexão sobre "Democracia e dignidade humana", que se conclui com uma chamada ao princípio de realidade a todos os que celebrávamos entusiasticamente o fim o período autoritário com a proclamação da Constituição cidadã:

Podemos pois afirmar, com absoluta certeza, que qualquer intento de efetivação de uma democracia real coloca em primeiro plano as exigências ética da ação política. É nesse plano que irá decidir-se, afinal, o êxito da experiência democrática e, com ele, o destino da liberdade nas sociedades contemporâneas, vem a ser, o próprio destino do homem político, como ser dotado de uma essencial dignidade. (LIMA VAZ, 1988a, p. 22).

Esse texto, juntamente com o breve e denso Editorial sobre "Democracia e sociedade", publicado nos albores da transição democrática (LIMA VAZ, 1985), fecundaram enormemente a minha reflexão sobre a democracia, a começar pela conferência feita na Semana Filosófica comemorativa dos sessenta anos da Faculdade de Filosofia da Companhia de Jesus e dos oitenta anos de vida do Padre Vaz. Nessa conferência, intitulada "Democracia e filosofia do agir humano", posteriormente publicada em volume organizado por João A. Mac Dowell, ao refletir sobre os desafios para a compreensão e para a ação decorrentes do conceito vaziano de democracia formulado nos dois textos acima citados, considerei ter confirmado

minha hipótese de que o desafio de compreender seu [de Lima Vaz] conceito de democracia como um verdadeiro conceito filosófico, do qual procede a exigência de compreensão adequada da relação entre ética e política, só encontrará resposta satisfatória no interior de uma análise filosófica da ação humana" (PERINE, 2002, p. 326) ${ }^{5}$.

A análise filosófica da ação humana encontra sua primeira expressão sistemática na Antropologia filosófica. O tomo I da Antropologia Filosófica foi publicado em 1991 e o tomo ll em 1992. Na "Advertência preliminar" que abre o primeiro tomo o Padre Vaz informa a seus leitores que a primeira versão do livro foi redigida como texto básico para o curso de Antropologia Filosófica ministrado no Departamento de Filosofia da Faculdade de Filosofia e Ciências Humanas da UFMG, de 1968 a 1972. Informa ainda que uma versão atualizada foi preparada para o curso ministrado em 1989 e 1990 na Faculdade de Filosofia do Centro de Estudos Superiores da Companhia de Jesus, hoje Faculdade de Filosofia e Teologia (FAJE). Como se vê, a obra passou por um período de elaboração de mais de 20 anos e foi amplamente "testada" em diferentes públicos de estudantes de filosofia. Além desse dado, por si só expressivo da quali-

\footnotetext{
${ }^{4}$ Síntese Nova Fase, n. 55, 1991. Outros textos de autores brasileiros e estrangeiros enviados em homenagem ao Padre Vaz foram publicados no seguinte volume da revista: Síntese Nova Fase, n. 56, 1992.

${ }^{5}$ Ver também (PERINE, 2013).
} 
dade da obra, note-se que a Antropologia é a primeira obra, sem sentido estrito, publicada pelo Padre Vaz. O volume de Escritos de filosofia I (Problemas de fronteira), de 1986, e o segundo volume dos Escritos de filosofia (Ética e cultura), de 1988, são coletâneas de textos anteriormente publicados, de modo que a Antropologia filosófica é a primeira obra sistemática do conjunto da obra vaziana. $E$, pelo que foi dito acima, trata-se de uma obra que já nasceu madura! Como comprovação dessa afirmação, cito as palavras do Pare Vaz, na Introdução da obra, ao definir as três tarefas fundamentais a serem cumpridas por uma Antropologia filosofia:

a elaboração de uma ideia do homem que leve em conta, de um lado, os problemas e temas presentes ao longo da tradição filosófica e, de outro, as contribuições e perspectivas abertas pelas recentes ciências do homem; uma justificação crítica dessa ideia, de sorte a que possa apresentar-se como fundamento da unidade dos múltiplos aspectos do fenômeno humano implicados na variedade das experiências com que o homem se exprime a si mesmo, e investigados pelas ciências do homem; uma sistematização filosófica dessa ideia do homem tendo em vista a constituição de uma ontologia do ser humano capaz de responder ao problema clássico da essência: o que é o homem? (LIMA VAZ, 1991, p. 10 s.).

Mas, a análise filosófica da ação humana seria plenamente formulada na obra que, modestamente, foi intitulada Introdução à ética filosófica, em dois volumes. O primeiro volume contém um primeiro capítulo dedicado à natureza e estrutura do campo ético, no qual o Padre Vaz reelabora sinteticamente os dois primeiros capítulos dos Escritos de filosofia II (Ética e cultura), seguido de ampla sinopse histórica, que vai da ética antiga aos rumos da ética pós-kantiana. Essa obra, como adverte o autor no Prefácio, que não é "um livro para o grande público", fruto de vários anos de magistério na UFMG e no Centro de Estudos Superiores da Companhia de Jesus em Belo Horizonte, começou a ser preparada para a edição por minha iniciativa, quando solicitei que um dos meus alunos, também aluno do Padre Vaz, digitasse o caderno do curso de ética do Padre Vaz. A esse aluno, Carlos Viana, ele faz um "agradecimento especial" no Prefácio ao primeiro volume (LIMA VAZ, 1999, p. 9).

O segundo volume é "dedicado à exposição sistemática dos princípios e categorias fundamentais que estrutura a Ética como ciência do ethos", e tem em vista "verificar teoricamente essa estrutura conceptual, desenvolvendo-a num discurso cuja unidade deverá obedecer a um princípio unificador, qual seja, a própria práxis humana na forma da Razão prática e regida por invariantes ônticos que a constituem como tal, independentemente das particularidades históricas, culturais, conjunturais ou individuais que condicionam seu exercício" (LIMA VAZ, 2000, p. 7). A análise filosófica da ação humana é decalcada nas categorias da Antropologia filosófica, segundo as estruturas subjetiva, intersubjetiva e objetiva do agir ético e da razão prática na vida ética.

Na vasta produção bibliográfica do saudoso Padre Vaz, o tema da ética ocupou um lugar privilegiado. Além dos já citados Escritos de filosofia II, com o subtítulo "Ética e Cultura", e dos volumes IV e V dos Escritos de filosofia, chamados de Introdução à Ética filosófica, dão amplo testemunho disso uma dezena de artigos, editoriais, verbetes e capítulos de livros nos quais aparecem os termos ética, ethos e moral ${ }^{6}$. Essa rigorosa e extensa elaboração filosófica do Padre Vaz não só no campo da ética, mas também da metafísica, fecundou a minha reflexão filosófica ${ }^{7}$, como também abriu para mim a possibilidade de orientar pesquisas de mestrado e doutorado. A primeira tese de doutorado que orientei, de Rubens Godoy Sampaio, intitulada

\footnotetext{
${ }^{6}$ Ver a bibliografia de e sobre Lima Vaz em: (SAMPAIO, 2006, p. 336-341); (RIBEIRO, 2012, p. 197-199); (OLIVEIRA, 2013, p. 281-286); (SOUSA, 2014, p. 199-211).

7 Ver (PERINE, 2002; 2007).
} 
Metafísica e modernidade. Método e estrutura, temas e sistema em Henrique Cláudio de Lima Vaz (SAMPAIO, 2006), tornou-se uma obra de referência nos estudos vazianos. No Programa de Estudos Pós-Graduados em Filosofia de Pontifícia Universidade Católica de São Paulo, sob minha orientação, já concluíram dissertações de mestrado Paulo Raphael Oliveira de Andrade sobre "A Antropologia Filosófica de Henrique Cláudio de Lima Vaz como superação do reducionismo antropológico", em 2017, e Luiz Fernando dos Santos sobre "Metafísica: retorno às origens da filosofia em de Lima Vaz" em 2019. Orientei também duas teses de doutorado: a de Juliano Almeida de Oliveira, sobre "Transcendência e Religião no pensamento de H. C. de Lima Vaz", em 2014, e a de Maria Celeste de Sousa, em 2009, sobre A Comunidade Ética: reconhecimento, consenso e sociedade em Henrique Claudio de Lima Vaz, que foi publicada na Coleção Estudos Vazianos da Faculdade de Filosofia dos Jesuítas (SOUSA, 2014).

Uma última reminiscência da presença do Padre Vaz em meu caminho filosófico antes de concluir. Em 1990 Padre Vaz publicou na Revista Síntese uma resenha do grande livro de Giovanni Reale sobre a nova interpretação de Platão promovida pela assim chamada Escola de Tübingen (REALE, 2004), na qual afirmava:

O livro de Reale é um passo importante e, talvez, definitivo, no sentido da recuperação das "doutrinas não-escritas" e da sua articulação às linhas fundamentais do pensamento de Platão tal como pode se reconstituído a partir do texto dos Diálogos. Mas seria ingênuo supor que a tarefa hermenêutica em torno do texto de Platão tenha enfim resolvido seus grandes problemas. A bibliografia platônica é um campo sem fim justamente porque o texto de Platão e tudo o que nos foi legado em seu nome formam um tesouro inesgotável. Desse tesouro Reale nos oferece agora uma soma rara de riquezas. Mas muitas ficam a descobrir. (LIMA VAZ, 1990, p. 113).

Como estudioso de Platão, Padre Vaz intuiu que o livro de Reale apontava para um fecundo campo de estudos no âmbito dos estudos platônicos. Instigado por ele, empreendi a tradução do volume de Reale, na qual trabalhei durante dois anos. O volume foi publicado em 1997, quando eu já havia me desligado da Companhia de Jesus. A repercussão do livro de Reale na comunidade de estudiosos de Platão em nossa academia foi nula: nenhuma resenha nos periódicos acadêmicos, exceto uma matéria no Jornal da USP. Por ocasião dos funerais do Padre Vaz em Belo Horizonte, em 2002, encontrei com o Prof. Raul Landim, da UFRJ, um dos primeiros discípulos do Padre Vaz egressos da Ação Católica, a quem manifestei minha estupefação diante do fato. Ele então me sugeriu que apresentasse ao CNPq um projeto para bolsa de produtividade em pesquisa sobre a questão das doutrinas não escritas de Platão. O projeto foi aprovado e durante 12 anos desenvolvi estudos sobre a questão, que resultaram na publicação do volume Platão não estava doente, que dediquei ao Padre Vaz, in memoriam, e a meus amigos incomparáveis Livio Rossetti, Maurizio Migliori e Thomas Szlezák (PERINE, 2014).

Concluo essa reminiscência da presença do Padre Vaz no meu caminho filosófico com uma evocação ao volume que organizei, reunindo contribuições apresentadas em dois eventos em homenagem ao Pe. Vaz, realizados para a celebração de um ano de seu falecimento: Diálogos com a cultura contemporânea (PERINE, 2003). Creio que o maior legado da obra filosófica do Padre Vaz para o diálogo com a cultura contemporânea seja, precisamente, o seu empenho (no sentido hegeliano do "esforço do conceito") na compreensão do nosso tempo. Como ele escreveu em memorável texto intitulado "Ética e justiça: filosofia do agir humano", de 1996, na Revista Síntese, o esforço do conceito consiste em "tentar encontrar os núcleos de inteligibilidade que se ocultam sob as aparências e, se possível, ordená-los num discurso coerente". Ao fazer isso, segundo o Padre Vaz, "a única missão que a filosofia pode assumir é oferecer à prática critérios fundados em razão e tendo em vista fins racionais para que, obedecendo-os, ela possa 
se exercer como prática sensata" (LIMA VAZ, 1996, p. 438). Tendo realizado de maneira exemplar a missão que ele atribui à filosofia, a sua obra é um convite permanente ao diálogo com a cultura contemporânea em vista da compreensão de seus problemas.

À memória do amigo dileto, meu afeto, minha admiração e meu reconhecimento.

\section{Referências}

LIMA VAZ, H. C. de. Democracia e sociedade. Síntese Nova Fase, n. 33, 1985. p. 5-14.

LIMA VAZ, H. C. de. Escritos de Filosofia II. Ética e Cultura. São Paulo: Edições Loyola, 1988.

LIMA VAZ, H. C. de. Democracia e dignidade humana. Síntese Nova Fase, n. 44, 1988a. p. 11-25.

LIMA VAZ, H. C. de. Um novo Platão? Síntese Nova Fase, n. 50, 1990. p. 101-113.

LIMA VAZ, H. C. de. Morte e vida da filosofia. Síntese Nova Fase, n. 56, 1991a. p. 677-691.

LIMA VAZ, H. C. de. Antropologia filosófica I, São Paulo: Loyola, 1991.

LIMA VAZ, H. C. de. Antropologia filosófica II, São Paulo: Loyola, 1992.

LIMA VAZ, H. C. de. Ética e justiça: filosofia do agir humano. Síntese Nova Fase, n. 75, 1996. p. 437-454.

LIMA VAZ, H. C. de. Escritos de filosofia IV. Introdução à ética filosófica 1. São Paulo: Loyola, 1999.

LIMA VAZ, H. C. de. Escritos de filosofia V. Introdução à ética filosófica 2. São Paulo: Loyola, 2000.

LIMA VAZ, H. C. de. Contemplação e dialética nos diálogos platônicos. Trad. Juvenal Savian Filho, São Paulo: Loyola, 2012.

MIGLIORI, M. L'uomo fra piacere, intelligenza e Bene. Commentario storico-filosofico al "Filebo" di Platone. Milano: Vita e Pensiero, 1993.

OLIVEIRA, C. M. R. de. Metafísica e ética. A filosofia da pessoa em Lima Vaz como resposta ao niilismo contemporâneo. São Paulo: Loyola, 2013.

PERINE, M. Ética e sociedade. Razão teórica versus razão técnica. Síntese Revista de Filosofia, n. 93, 2002a. p. 49-69.

PERINE, M. Democracia e filosofia do agir humano. Observações sob uma luminosidade que permite a visão. In: . MAC DOWELL, J. A. (Org.). Saber filosófico, história e transcendência. Homenagem ao Pe. Henrique Cláudio de Lima Vaz, SJ, em seu $80^{\circ}$ aniversário. São Paulo: Loyola, 2002. p. 317-332.

PERINE, M. (Org.). Diálogos com a cultura contemporânea. Homenagem ao Pe. Henrique C. de Lima Vaz, SJ. São Paulo: Loyola, 2003.

PERINE, M. A ética e a crise da modernidade. Uma leitura a partir da obra de Henrique C. de Lima Vaz. Cadernos IHU Ideias, v. 88, 2007. p. 1-22.

PERINE, M. Um Platão no caminho filosófico de Lima Vaz. Síntese Revista de Filosofia, n. 123, 2012. p. 9-29.

PERINE, M. Filosofia e violência. Sentido e intenção da filosofia de Éric Weil. São Paulo: Loyola, 1987 (2a edição 2013).

PERINE, M. O conceito de democracia em Henrique Cláudio de Lima Vaz e Norberto Bobbio: desafios para a ação. Em:TOSI, G. (Org.). Norberto Bobbio: democracia, direitos humanos, guerra e paz. João Pessoa: Editora da UFPB, 2013. p. 307-323. 
PERINE, M. Platão não estava doente. São Paulo: Loyola, 2014.

REALE, G. Para uma nova interpretação de Platão. Releitura da metafísica dos grandes diálogos à luz das "doutrinas não-escritas". Trad. M. Perine. São Paulo: Loyola, 1997 (2a edição 2004).

RIBEIRO, E. V. Reconhecimento ético e virtudes. São Paulo: Loyola, 2012.

SAMPAIO, R. G. Metafísica e modernidade. Método e estrutura, temas e sistema em Henrique Claudio de Lima Vaz. São Paulo: Loyola, 2006.

SOUSA, M. C. de. Comunidade ética. Sobre os princípios ontológicos da vida social em Henrique Claudio de Lima Vaz. São Paulo: Loyola, 2014.

Sobre o autor

\section{Marcelo Perine}

Doutor em Filosofia pela Pontificia Universtià Gregoriana de Roma (PUG). Professor Associado da Pontifícia Universidade de São Paulo (PUCSP).

Recebido em: 24/08/2019.

Aprovado em: 27/10/2020.
Received: 24/08/2020.

Approved: 27/10/2020. 